\title{
Job Titles of Medical Technologist Managers in a Hierarchical System and Team System
}

\author{
Bon-Kyeong Koo \\ Department of Laboratory Medicine, Samsung Medical Center, Seoul, Korea
}

\section{계층제와 팀제에서 임상병리사 관리자 명칭}

\author{
구본경 \\ 삼성서울병원 진단검사의학과
}

\begin{abstract}
In the 2000's, due to a change in hospital management strategy, the organizational structure shifted from a hierarchical system to a team system. While the hierarchical system is characterized by being activity centered, job title linked, and vertically managed, the team system is characterized by being competency centered, job title segregated, and horizontally managed. The job titles of medical technologist manager was surveyed three times in 1997, 2007, and 2017. It has been confirmed through staff members working at 24 hospitals in more than 500 beds in the metropolitan area. The results of job titles follow are as follow: "Team Leader; Part Leader" 14/24 (59\%), "Chief Technologist; Area Head Technologist" $7 / 24$ (29\%), and "Chief” $3 / 24$ (12\%). The present authors propose an alternative name based on the team system to refine the three job titles currently used by medical technologists. First, the Chief Technologist is unclear if it refers to the Technologist General Manager or Technologist Manager. The Chief Technologist should be changed to "Team Leader". Second, given that Area Head Technologist or Section Chief are on the same position as Head Nurse, we suggest that Area Head Technologist or Section Chief should be changed to "Part Leader". Third, while the organization regulation is marked merely as Department of Laboratory Medicine according to the hierarchical system, it is marked as Laboratory Medicine Team according to the team system. Medical technologists come to have more belongingness, feeling of solidarity, and intimacy under the team system.
\end{abstract}

Key words: Job title, Team system, Team leader, Part leader, Laboratory Medicine Team

This is an Open Access article distributed under the terms of the Creative Commons Attribution Non-Commercial License (http://creativecommons.org/licenses/by-nc/4.0) which permits unrestricted non-commercial use, distribution, and reproduction in any medium, provided the original work is properly cited.

Copyright @ 2018 The Korean Society for Clinical Laboratory Science. All rights reserved.
Corresponding author: Bon-Kyeong Koo Department of Laboratory Medicine, Samsung Medical Center, 81 Irwon-ro, Gangnam-gu, Seoul 06351, Korea

Tel: 82-2-3410-2691

Fax: 82-2-3410-0022

E-mail: bonkyung.koo@samsung.com

Received: December 18, 2017

Revised: January 5, 2018

Accepted: January 16, 2018

\section{서 론}

“병원”은 자본집약적, 기술집약적, 노동집약적인 사업체로 의사, 간호사, 약사, 의료기사, 기술직, 행정직, 기능직 등 매우 다양한 인력들이 모여 팀워크로 의료서비스를 제공한다[1]. "관 리자"의 단계는 조직계층에 따라 고위관리자(최고경영자), 중 간관리자, 초급관리자로 구분할 수 있다[2]. “직함” 은 조직사회 에 상대방의 직위나 직책의 명칭을 의미한다. 정부는 "기술직
공무원 직급명칭”과 “6급 이하 공무원 대외직명”에 대한 개선 책을 발표하였다. 기술직 공무원 직급명칭인 기감, 기정, 기좌 등의 보수적 용어는 일반인들이 정확한 직함을 알기 어렵고 직 원들조차도 사용을 기피하는 등 사기저하의 요인이었다. 1992 년 “공무원 임용령” 개정을 통해 기술직 공무원 직급명칭을 폐 지하고 행정직 공무원과 동일한 직급명칭을 부여하여 1급 관리 관, 2 급 이사관, 3 급 부이사관, 4 급 서기관, 5 급 사무관, 6 급 주 사, 7급 주사보, 8급 서기, 9급 서기보로 변경하였다[3]. 이에 따 
른 영향으로 대학 등에서도 기술직 직급명칭을 행정직 직급명 칭과 동일하게 적용시켜 참여, 부참여, 참사, 부참사, 주사, 부주 사, 서기, 부서기로 변경하거나 참여, 참사 등의 보수적 용어를 폐지하고 부장, 차장, 과장, 대리의 직위명칭을 직급에 적용시킨 기관도 있다. 또한 2010년 정부는 “6급 이하 실무 공무원들에 대한 대외직명 운영지침”을 통해 6급 이하 공무원들에게 주무 관 명칭을 부여하였다[4]. “병원조직체계"는 의료전문가의 영 향력이 큰 「진료처(處) 또는 진료부(部); 진료과(科)」 단위의 진료부서와「부(部); 과(課)」 단위의 지원부서로 편성되어 있 다. 지원부서는 필요에 따라 하위조직인「계(係)」를 두기도 한다. 1998년 정부는 하위조직인「계(係)」 제를 폐지하고 대 외직명으로 “팀제”를 도입하였다. 1990년대는 기업들이 노사 관계안정화와 국제경쟁력강화를 위한 새로운 인사 정책을 추진 하였고 전통적 계층제(부과제)를 탈피하여 성과지향적 팀제를 도입하고 있었다. “팀제”는 1999년 일부 병원이 부, 과, 계 단위 를 팀, 파트(유닛) 단위로 개편하고 보직자의 직위와 직책을 분 리운영, 보직임기, 순환보직, 무보직 승급 등이 포함된 新인사제 도를 도입하였다[5,6]. 본 연구는 병원에 팀제 도입 시기를 전후 로 임상병리사 관리자 명칭을 비교한 서술적 조사이며, 향후 명 칭 선택이나조직 운영에 기여하고자 함을 목적으로 하고 있다.

\section{재료 및 방법}

임상병리사 관리자 명칭을 조사하기 위해 직급체계, 과학기 술인력, 일본·미국 사례를 요약 정리하였다.

\section{1. 직급체계}

직급체계는 급여, 신분명칭 및 권한 등을 부여하고 운영하는
인사제도를 의미한다. “직급”은 등급과 연공서열, “직위”는 지 위와 직무책임, “직책”은 보직과 의사결정 관련 용어로 정의할 수 있다. 2015년 정부는 “정부조직의 영어명칭에 관한 규칙” 제정 을 통해 조직이 기능과 위상을 파악하고 국제적인 통용의 가능성 을 우선으로 "실, 처, 본부는 office; 국은 bureau; 부, 단은 department; 과(課)는 division; 팀은 team” 으로 정하였으며 “계 의 영어명칭인 section"은 사용하지 않고 있다[7] (Table 1). 조직 이나부서장의 영어명칭은 정부 부처, 민간 기업, 외국계 기업에 따 라 다소 다르게 표현되고 있다. 부(department, division); 課 (department, division, section); 계(section, subsection); 부장 (Director, Executive manager, General manager, Senior manager); 사장(President, Managing director, General manager)에 대한 영어 번역은 한국, 일본, 미국, 영국에서 차이가 있다. 병원 진료과장(科長)과 의과대학교 학과장(科長) 명칭은 department chief, department head 보다 department chair 표 현을 사용하고 있다. 일반적인 병원업계의 직급체계는 Table 2과 같다.

Table 1. Rank system of public officials

\begin{tabular}{ll}
\hline \multicolumn{1}{c}{ Grade } & \multicolumn{1}{c}{ Position } \\
\hline 1G Chief administrator & Deputy minister, Office (실장) \\
2G Chief commissioner & Director general, Bureau (국장) \\
3G Deputy commissioner & $\begin{array}{c}\text { Deputy director general, Bureau / } \\
\text { Director, Division (부국장/課장) }\end{array}$ \\
4G Secretary official & Director, Division (課장) \\
5G Chief official & Head of team (팀장) \\
6G Junior official & \\
$7 G$ Assistant official & \\
8G Clerk & \\
$9 G$ Assistant clerk & \\
\hline
\end{tabular}

6-9G external name: Desk officer.

Table 2. Job grading system in typical hospital

Grade

\begin{tabular}{l}
\hline Executive members \\
\hline Staff members \\
$1-9$ (E9, E8, E7, E6, E5, E4, E3, E2, E1) \\
$1-6(G 6, G 5, G 4, G 3$, G2, G1) \\
Associate - Junior - Senior - Principal \\
Junior - Senior - Master - Leader \\
Junior - Senior - Manager
\end{tabular}

President

Vice president

Senior managing director

Managing director

Director

General managerr

Deputy general manager

Manager

Assistant manager

Associate

Position

Job titles can be expressed differently depending on the government, company, industry, and Anglosphere.

Abbreviations: CEO, chief executive officer; COO, chief operating officer; CMO, chief medical officer; CAO, chief administrative officer; CNO, chief nursing officer.

Similar words: CxO, C-level officer, C-suite officer; Chief, Head. 


\section{2. 과학기술인력의 직무등급}

1993년 고용노동부 주최로 ㅎ⽄ㅎ경제 5개년계획 추진에 따른 최종보고서에 의하면 과학기술인력 분류에서 "과학자(scientist), 기술공학자(engineer), 기사(technician), 기능사(Craftsman)” 는 해당 분야의 학위나 자격으로 직무를 구분하며 과학자는 대 학원졸업 수준, 기술공학자는 대학교졸업 수준, 기사는 전문대 학졸업 수준, 기능사는 고등학교졸업 수준이라고 발표하였다 [8]. 미국 노동부 노동통계국 직업현황에 따르면 각종 기술자 (techs: technologist and technician)의 경우 직무에 따라 학 사 또는 준학사 학위를 요구하고 있다[9]. 우리나라 임상병리사 에 해당하는 영국 biomedical scientist (BMS)는 1994년, 미국 clinical laboratory scientist (CLS)는 1993년 및 medical laboratory scientist (MLS)는 2009년부터 “과학자” 명칭을사 용하고 있으며 사회적으로 승인을 받았다는 점이 주목할 일이 다[10-12].

\section{3. 외국 임상병리사 관리자 명칭}

\section{1) 일본 사례}

일본 임상검사기사(臨床檢査技師) 관리자 명칭의 경우 다수 병원에서 “임상검사기사장 및 부임상검사기사장, 계장, 주임임 상검사기사”를 사용하고 있다[13,14] (Table 3).

Table 3. Job titles of laboratory manager in Japan (2017)

\begin{tabular}{cc}
\hline $\begin{array}{c}\text { Department of Clinical Laboratory, } \\
\text { Kyoto Prefectural University } \\
\text { Hospital }\end{array}$ & $\begin{array}{c}\text { Department of Cytology, } \\
\text { Clinical Pathology Center, } \\
\text { Cancer Institute Hospital of } \\
\text { Japanese Foundation for } \\
\text { Cancer Research }\end{array}$ \\
\hline $\begin{array}{c}\text { Head medical technologist head medical technologist } \\
\text { Chief medical technologist }\end{array}$ & $\begin{array}{c}\text { Head of cytotechnologist } \\
\text { Deputy head of cytotechnologist } \\
\text { Senior cytotechnologist }\end{array}$ \\
\hline
\end{tabular}

\section{2) 미국 사례}

미국 "medical technologist, clinical laboratory scientist, medical laboratory scientist; cytotechnologist; histotechnologist; cytogenetic technologist; molecular biology technologist" 의 경우 관리자 명칭으로 "manager, supervisor" 을 선호하고 있다[15] (Table 4). 미국임상병리학회(American Society for Clinical Pathology, ASCP)는 1988년부터 최근의 임금 데이터를 제공하고 전국 임상검사실의 인력 부족의 정도 와분포를 결정하기 위해 임금 및 공석 조사를 매년 실시하고 있 다. 1988 2012년 자료의 경우 "manager; supervisor; staff" 로 직위를 구분하였고, 2013년 자료부터는 "director; manager; supervisor; lead; staff” 로 직위를 세분화하여 발표 하고 있다[16]. 미국임상검사경영관리협회(Clinical Laboratory Management Association, CLMA)의 회원의 구성은 “director; manager; supervisor; staff” 로 되어 있다[17].

\section{결 과}

임상병리사 관리자 명칭은 1997년, 2007년, 2017년 세 차례 에 걸쳐서 조사되었다. 수도권에 소재한 500 병상 이상 24 개 병 원에서 근무하는 관리자나 담당자 등을 통해 조사되었다. 관리 자 보직은 병원장이 임용하는 공식 보직과 검사실에서 자체 운 영하는 非공식 보직이 있으며 보직자 수도 병원의 환경에 따라 차이가 있었다. 최근 미국 임상병리사계에서 주요쟁점이 되고 있는 인증기관, 박사학위, 검사실책임자에 대하여 조사하였다.

\section{1. 팀제 도입 전 임상병리사 관리자 명칭}

1997년 임상병리사 관리자 명칭은 대다수 병원에서 "기사장, 실장; 부기사장, 감독기사, 수석기사, 주임기사, 계장”을 사용하 고 있었다. (1) 기사장, 실장 영문은 chief technologist로 표현 한다. 기사장 영문을 head technologist로 표현하지 않는 이유

Table 4. Job titles of clinical laboratory personnel in USA (2017)

\begin{tabular}{|c|c|c|c|c|}
\hline CLIA '88 job title & Laboratory director & Technical supervisor & General supervisor & Testing personnel \\
\hline Equivalent job title & $\begin{array}{l}\text { Laboratory director } \\
\text { (usually a pathologist) }\end{array}$ & $\begin{array}{l}\text { Section director* } \\
\text { Laboratory manager } \\
\text { Laboratory supervisor } \\
\text { Chief technologist }\end{array}$ & $\begin{array}{l}\text { Section supervisor } \\
\text { Section chief } \\
\text { Section head }\end{array}$ & $\begin{array}{c}\text { Medical technologist } \\
\text { Clinical laboratory scientist } \\
\text { Medical laboratory scientist } \\
\text { Cytotechnologist } \\
\text { Histotechnologist } \\
\text { Cytogenetic technologist } \\
\text { Molecular biology technologist }\end{array}$ \\
\hline
\end{tabular}

*Special qualification (Transfusion medicine, Histocompatibility, Cytogenetics, Cytopathology, Histopathology, Oral Pathology). Sources: Estridge BH, et al. Basic medical laboratory techniques, 6th ed, Delmar cengage learning, 2011; Clinical Laboratory Improvement Amendments of 1988, Final Rule. Federal Register, Vol. 7, No. 40, February 28, 1992. 
Table 5. Job titles of laboratory manager in metropolitan area hospitals (2017)

\begin{tabular}{|c|c|c|}
\hline $\begin{array}{l}\text { Hospital } \\
(\mathrm{N}=24)\end{array}$ & Manager level & Section supervisor level \\
\hline ASH & Chief technologist $\rightarrow$ Team leader (기사장 $\rightarrow$ 팀장) & Lead technologist $\rightarrow$ Unit manager (주임기사 $\rightarrow$ 유닛장) \\
\hline CUSH & Chief technologist $\rightarrow$ Team leader (기사장 $\rightarrow$ 팀장) & Lead technologist $\rightarrow$ Unit manager (주임기사 $\rightarrow$ 유닛장) \\
\hline HYUH & Chief technologist $\rightarrow$ Team leader (기사장 $\rightarrow$ 팀장) & $\begin{array}{l}\text { Supervising technologist, Lead technologist } \\
\quad \rightarrow \text { Part leader (감독기사, 주임기사 } \rightarrow \text { 파트장) }\end{array}$ \\
\hline IHUH & Chief technologist $\rightarrow$ Team leader (기사장 $\rightarrow$ 팀장) & $\begin{array}{l}\text { Supervising technologist, Lead technologist } \\
\quad \rightarrow \text { Part leader (감독기사, 선임기사 } \rightarrow \text { 파트장) }\end{array}$ \\
\hline $\mathrm{KHUH}$ & Chief technologist $\rightarrow$ Team leader (기사장 $\rightarrow$ 팀장) & Lead technologist $\rightarrow$ Part leader (주임기사 $\rightarrow$ 파트장) \\
\hline KKUH & Team leader (팀장) & Part leader (파트장) \\
\hline AJUH & Chief technologist $\rightarrow$ Team leader (기사장 $\rightarrow$ 팀장) & Section chief $\rightarrow$ Part leader (계장 $\rightarrow$ 파트장) \\
\hline YSUH & Chief technologist $\rightarrow$ Team leader (기사장 $\rightarrow$ 팀장) & Section chief $\rightarrow$ Part leader (계장 $\rightarrow$ 파트장) \\
\hline GSH & $\begin{array}{l}\text { Chief technologist } \rightarrow \text { Technical senior manager } \\
\quad \rightarrow \text { General manager (기사장 } \rightarrow \text { 팀장) }\end{array}$ & $\begin{array}{l}\text { Assistant chief technologist } \rightarrow \text { Technical manager } \\
\quad \rightarrow \text { Manager (부기사장 } \rightarrow \text { 파트장) }\end{array}$ \\
\hline SSH & Chief (실장) & Assistant chief (수석기사 $\rightarrow$ 파트장) \\
\hline $\mathrm{SCHUH}$ & Chief technologist $\rightarrow$ Team leader (기사장 $\rightarrow$ 팀장) & $\begin{array}{l}\text { Supervising technologist, Lead technologist } \\
\quad \rightarrow \text { Section chief (감독기사, 수석기사 } \rightarrow \text { 계장) }\end{array}$ \\
\hline $\mathrm{CAUH}$ & Chief technologist $\rightarrow$ Team leader (기사장 $\rightarrow$ 팀장) & \\
\hline EJUH & Chief technologist $\rightarrow$ Team leader (기사장 $\rightarrow$ 팀장) & \\
\hline GCUH & Chief (실장) & \\
\hline $\mathrm{HIH}$ & Chief technologist $\rightarrow$ Team leader (기사장 $\rightarrow$ 팀장) & \\
\hline HLUH & Chief technologist $\rightarrow$ Team leader (기사장 $\rightarrow$ 팀장) & \\
\hline IJUH & Chief technologist (기사장 $\rightarrow$ 실장) & \\
\hline KRUH & Chief technologist (기사장) & Lead technologist $\rightarrow$ Assistant team leader (주임기사 $\rightarrow$ 부팀장) \\
\hline DKUH & Chief technologist (기사장) & Part leader (파트장) \\
\hline SNUH & Chief technologist (기사장) & Area head technologist (수석기사) \\
\hline NCC & Chief technologist (기사장) & Area head technologist (수석기사) \\
\hline $\mathrm{NHISIH}$ & Chief technologist (기사장) & Area head technologist (수석기사) \\
\hline $\mathrm{NCCH}$ & Chief technologist (기사장) & \\
\hline EWUH & Chief technologist (기사장) & \\
\hline
\end{tabular}

Similar words: Team Leader, Team Manager; Part Leader, Part Manager; Unit Leader, Unit Manager.

는 수간호사 영문이 head nurse로 되어 있어서 기사장을 수간 호사와 같은 직위로 인식할 수 있기 때문이다. (2) 부기사장 영문 은 assistant chief technologist, 감독기사 영문은 supervising technologist, 수석기사 영문은 area head technologist, 계장 영문은 section chief로 표현한다. (3) 주임기사 영문은 lead technologist로 표현하는데 해당병원의 직원인사규정에 따라 서 차이가 있다. 간호사직종은 병원 내 인력 중에서 가장 큰 부서 이며 "간호부원장, 간호본부장, 간호부장; 간호과장; 간호계장, 수간호사; 주임간호사, 책임간호사; 평간호사”로 분류하고 있 다. 일부 병원의 경우 주임기사(lead technologist)가 수간호사 와 같은 직위임에도 非관리자인 주임간호사(charge nurse) 직 위로 인식할 수 있기에 주임기사를 수석기사로 변경한 사례도 있다. (4) 주목할 만한 명칭으로는 ASH 병원의 경우 "기사과장 (課長)", $\mathrm{GSH}$ 병원과 $\mathrm{SCH}$ 병원은 “기술부장(部長), 기술과장 (課長)" 직위가 있었다.

\section{2. 팀제 도입 후 임상병리사 관리자 명칭}

1994년 SSH 병원은 직위와 직책을 분리 운영하는 新인사제
도를 시행하였다. 1999년 ASH 병원은 팀제를 처음 도입하여 기 사장, 주임기사를 “팀장; 유닛장”으로 변경하였으며 이후 YUSH 병원은 2007년 기사장, 2004년 계장을 “팀장; 파트장” 으로 변경하였다. 전국적으로 유일하게 "기술부장, 기술과장" 을 사용하였던 세 기관중 GSH 병원과 SCH 병원은 2010년 “팀 장; 파트장”, $\mathrm{KRC}$ 혈액원은 2000년 팀장으로 변경하였다. 2017년에 조사한 임상병리사 관리자 명칭은 24개 병원 중 59\% (14/24)에서 “팀장; 파트장(유닛장)”, 29\% (7/24)에서 “기사 장; 수석기사”, $12 \%$ (3/24)에서 “실장”을 사용 중에 있다(Table 5). 임상병리사 관리자 명칭은 병상 규모, 임상병리사 수, 전문 의 상주 등에 따라 차이가 있지만 검사의학과 임상병리사들의 경우 “검사의학팀장, 검사의학실 팀장, 임상병리실장, 임상병 리검사실장”을 선호하고 있다.

\section{3. 계층제와 팀제에서 임상병리사 직위명칭}

임상병리사 직위명칭은 계층제를 시행하는 병원의 경우 "의 료기사장; 부의료기사장, 감독의료기사, 수석의료기사; 선임 의료기사, 책임의료기사; 평의료기사" 등으로 분류하고 있다. 
팀제를 시행하는 병원은 "1) 부장, 차장, 과장, 대리, 직원(주임 이하); 2) 부장, 차장, 과장, 선임, 직원(주임 이하); 3) 부장, 차장, 수석, 선임, 직원(주임 이하); 4) 부장, 차장, 선임, 책임, 직원(주 임 이하); 5) 수석, 책임, 선임, 직원(주임 이하)” 등의 새로운 직 위명칭으로 분류하고 있으며 직원들의 직위격상이나 직급격상 이 확대된 것이 특징이다.

\section{4. 계층제와 팀제에서 검사실 직제 명칭}

검사실 직제명칭은 계층제를 시행하는 병원의 경우 “검사의 학과, 병리과"로 표기하지만 팀제를 시행하는 병원은 검사의학 과, 병리과 산하 “검사의학팀, 검사의학실, 임상병리검사실; 병 리팀, 병리실, 병리검사실”로 표기하는 것이 특징이다.

\section{5. 미국 임상병리사계의 주요쟁점}

\section{1) 임상병리사의 자격 인증기관}

"Medical technologist, clinical laboratory scientist,

Table 6. Newly certified MLS(ASCP) (2017)

\begin{tabular}{|c|c|}
\hline NCA designation & $\begin{array}{c}\text { New ASCP BOC } \\
\text { designation }\end{array}$ \\
\hline $\begin{array}{c}\text { CLS(NCA) } \\
\text { CLSp(NCA) [CLSp-H, CLSp-I, CLSp-C, CLSp-M] } \\
\text { CLSp(NCA) [CLSp-CG, CLSp-MB] } \\
\text { CLSup(NCA) }\end{array}$ & 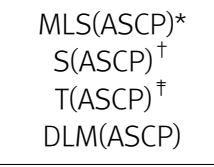 \\
\hline $\begin{array}{l}\text { *Merged CLS(NCA) and MT(ASCP) in 2009 } \\
\text { Immunohematology, Chemistry, Microbiology; } \\
\text { Molecular biology. } \\
\text { Abbreviations: NCA, National Credentialing Agen } \\
\text { Personnel; ASCP BOC, American Society for Clinical } \\
\text { of Certification; CLS, clinical laboratory scientis } \\
\text { laboratory specialist; CLSup, clinical laboratory } \\
\text { medical laboratory scientist; S, specialist; T, tec } \\
\text { Diplomate in laboratory management. } \\
\text { Source: American }\end{array}$ & $\begin{array}{l}{ }^{\dagger} \text { Hematology, } \\
{ }^{\dagger} \text { Cytogenetics, } \\
\text { cy for Laboratory } \\
\text { I Pathology Board } \\
\text { st; CLSp, clinical } \\
\text { supervisor; MLS, } \\
\text { chnologist; DLM, }\end{array}$ \\
\hline
\end{tabular}

medical laboratory scientist; cytotechnologist; histotechnologist; cytogenetic technologist; molecular biology technologist" 의 자격 인증기관으로 ASCP (American Society for Clinical Pathology), AAB (American Association of Bioanalysts), AMT (American Medical Technologists), NAACLS National Accrediting Agency for Clinical Laboratory Sciences), NCA (National Credentialing Agency for Laboratory Personnel)가 있다[18-21]. 2009년 $\mathrm{NCA}$ 는 해산되어 임상병리사(clinical laboratory scientist, genetic technologist) 자격 인증 업무를 $\mathrm{ASCP}$ 로 이관하였다 (Table 6).

\section{2) 임상병리사의 박사학위 프로그램}

미국임상검사과학회(American Society for Clinical Laboratory Science, ASCLS)는 2012년 변화하는 의료 시스템의 요 구를 충족시키기 위해 처음으로 임상검사과학(임상병리검사 학) 박사학위 프로그램(doctorate of clinical laboratory science, DCLS)를 도입하였다[22].

\section{3) “검사실책임자(laboratory director)" 의 자격}

1988년 제정된 임상검사개선법(clinical laboratory improvement amendments of 1988, CLIA '88) 법률에 "laboratory director, technical supervisor, general supervisor (Title $42>$ Chapter IV > Subchapter G > Part 493 > Subpart M)"에 대한 자격이 규정되어 있다[23,24]. CLIA '88에서는 非 의사 또는 非박사급 과학자가 단순검사나 중등도복잡성검사 업 무를 지시 • 감독할 수 있지만, 미국병리학회(College of American Pathologists, CAP)는 허용하지 않는다[25]. CAP에서는 단순검사, 중등도복잡성검사, 고도복잡성검사 업무를 의사 또

Table 7. Certified pathologists (2017)

\begin{tabular}{cl}
\hline \multicolumn{1}{c}{ Primary specialty certification } & \multicolumn{1}{c}{ Subspecialty certification } \\
\hline & Blood banking/Transfusion medicine \\
& Clinical informatics (in cooperation with the American Board of Preventive Medicine) \\
& Cytopathology \\
Hematopathology & Dermatopathology (in cooperation with the American Board of Dermatology) \\
Anatomical and clinical pathology & Neuropathology \\
Clinical pathology & Chemical pathology \\
& Medical microbiology \\
& Molecular genetic pathology (in cooperation with the American Board of Medical Genetics \\
& and Genomics) \\
Pediatric pathology
\end{tabular}

Source: American Board of Pathologists. 
Table 8. Qualified physicians for clinical laboratory director (2017)

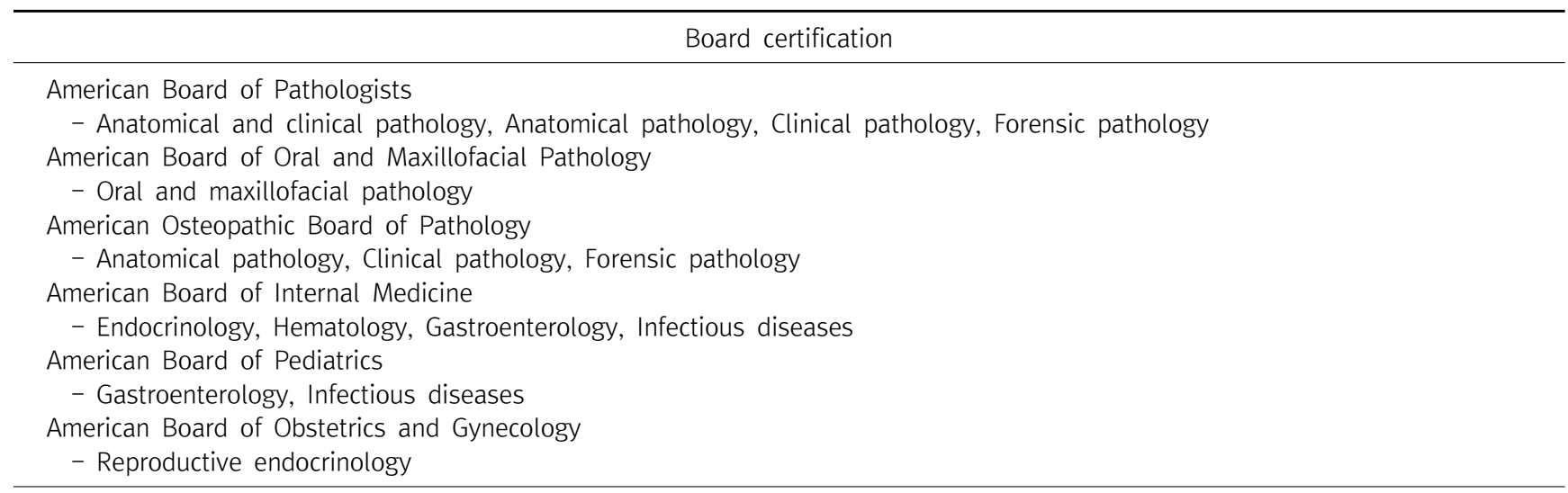

Source: Tennessee Department of Health.

Table 9. Qualified doctoral scientists for laboratory director of moderate and high complexity testing (2017)

Board certification

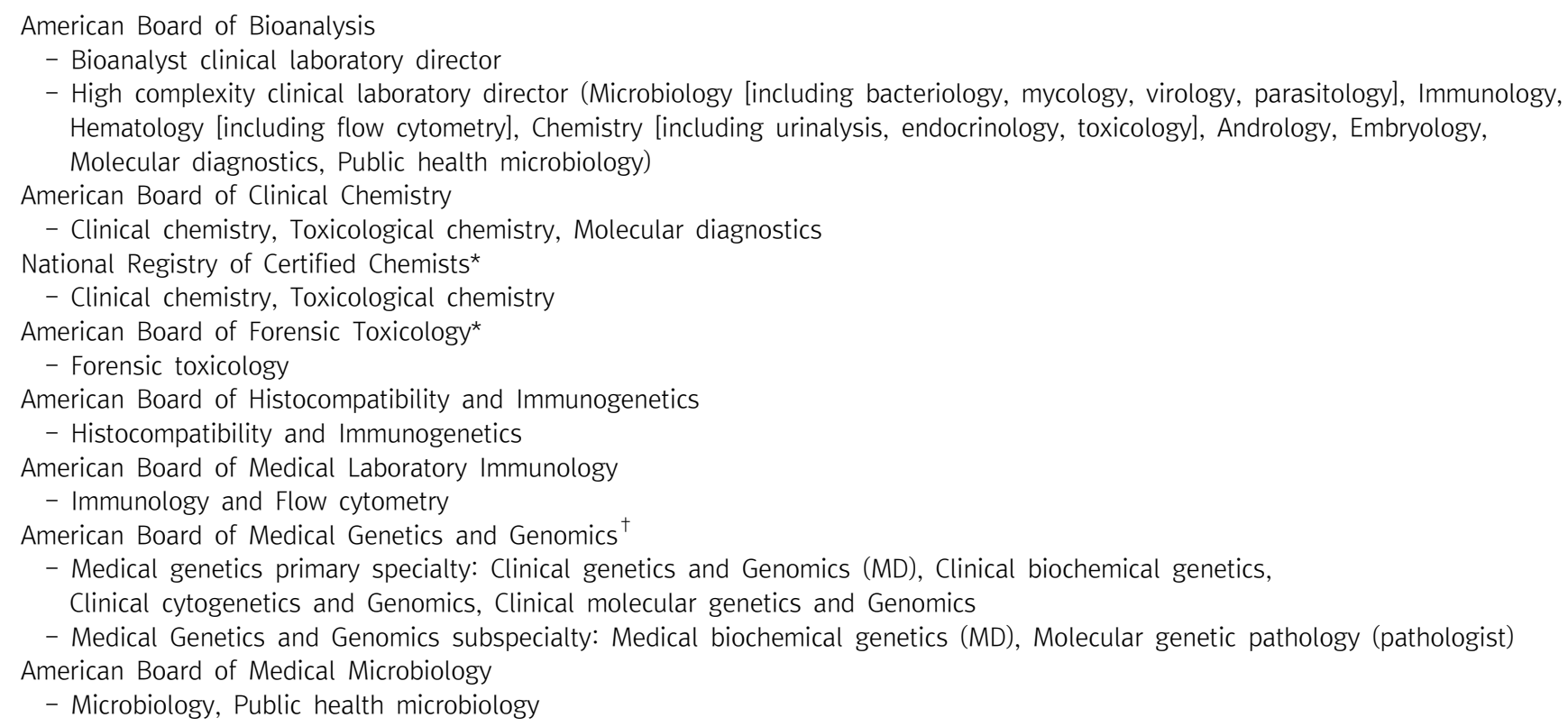

*Limited to individuals with a doctoral degree; ${ }^{\dagger}$ American Board of Medical Genetics and Genomics no longer offers initial certification in PhD medical genetics.

Abbreviations: MD, medical doctor; PhD, doctor of philosophy.

Sources: Tennessee Department of Health; American Board of Medical Speciality.

는 박사급 과학자가 지시 - 감독해야 한다. 검사실책임자는 병 리의사를 비롯한 의사(MD, medical doctor), 정골의사(DO, doctor of osteopathy), 족부의사(DPM, doctor of podiatric medicine), 박사급 과학자( $\mathrm{PhD}$, doctor of philosophy)로 제 한하고 있다[26,27] (Table 7, 8). 특히 박사급 과학자(doctoral scientist)는 화학, 물리학, 생물학 또는 임상검사과학 분야에서 박사학위(doctoral degree in chemical, physical, biological or clinical laboratory science)를 소지한 자로 인증기관에서 자
격을 취득한 후 보건복지부에 승인을 받아야 한다" [28,29] (Table 9).

\section{고 찰}

본 연구는 계층제와 팀제에서 임상병리사 관리자 명칭에 관한 자료이다. 임상병리사 관련 자격, 학회, 학문에 대한 명칭은 $\mathrm{KoO}$ 등[30]의 연구에서 국영문 일치된 명칭, 사회통념상 직관 인식되 
는 명칭이 중요하다고 발표하였다. 2000년대 병원경영전략 중 에서도 큰 변화는 계층제의 형태를 팀제로 전환된 점이라 할 수 있다. 계층제는 직무중심, 직위직책연계, 수직적 경력관리이며 팀제는 직능중심, 직위직책분리, 수평적 경력관리로 구조측면에 서 차이가 있다[31]. 초대형병원을 중심으로 시작된 新인사제도 는 크게 진료지원부서와 행정지원부서의 유기적이고 일원화된 조직명칭, 직위와 직책을 분리하여 직위는 직급에 상응한 직위명 칭으로 대별될 수 있다. 본 저자는 임상병리사들에게 적용하고 있는 세 가지 직위와직책명칭에 대하여 팀제를 기반으로 대안을 제시하고자 한다. 첫째, 기사장은 기사부장 또는 기사과장인지 지위가 불분명한 명칭이다. 기사장은 팀장으로 변경할 것을 제안 한다. 둘째, 수석기사 또는 계장이 수간호사와 같은 직위 수준이 라고 가정한다면, 수석기사 또는 계장을 파트장(유닛장)으로 변 경할 것을 제안한다. 셋째, 주임기사가 수간호사와 같은 직위 수 준이라고 가정한다면, 非관리자인 주임간호사와 “주임”이 한국 어 발음과 동일하기 때문에 적절하지 않다. 검사실 직제명칭은 직제규정, 직원인사규정, 노무관리 등에서 계층제와 팀제에서 차이가 있다. 계층제의 경우 과(科)로만 표기하지만, 팀제에서는 과(科) 산하 팀(또는 실)으로 표기하여 임상병리사들은 팀제를 통 해 소속감, 연대감, 친밀감을 더욱 갖게 된다. 대한진단검사의학 회 검사실 신임인증 심사점검표[32]에 기재되어 있는 책임전문 의는 검사실책임자(laboratory director, 진료과장)와 세부분야 책임자(section director, 세부분야전문의)를 표현하는 것이다. 심사점검표 문항번호 301.230에 있는 책임임상병리사의 자격 에서 “주임기사, 계장 등” 으로 표기되어 있는 것을 현실적 직급 체계에 맞게 “파트장(유닛장), 수석기사 등” 으로 변경해야 한다. 보건복지부 보건의료기술연구개발사업의 지원에 수행된 연구 과제(HMP-98-M-1-0015) "국내 임상병리검사실의 인력구조 및 운영 현황”에서 “임상병리사 관리자” 가 표현되었으며 임상병 리검사실의 규모는 임상병리사수를 기준으로 관리자 또는 세부 분야에 1명을 더한 6 명을 기본 단위로 구성하였고 소형검사실은 1 6명, 중형검사실은 7 13명, 대형검사실은 14 42명, 초대 형은 42 명 이상의 임상병리사가 근무하는 검사실로 분류하였다 [33,34]. 2015년 한국보건산업진흥원에서 발표한 “해외 진출 의 료기관(SNUH)의 인력운영 및 수요” 컨설팅 보고서에 따르면 chief technologist는 senior supervisor, area head technologist는 supervisor로 제시한 사례도 있다[35]. 다른 한편 산업 안전보건법 제13 14조에 있는 관리책임자와 관리감독자 명칭 은 검사실의 경우 관리책임자는 검사실책임자(laboratory director; 전문의), 관리감독자는 검사실관리자(laboratory manager; 임상병리사)와 검사실감독자(laboratory supervi- sor; 임상병리사)로 구분할 수 있으며 직무 역할에서 유사한 부분 이 있다[36]. 본 연구의 제한점은 직위나 직책명칭에 관련한 전문 가 컨설팅, 설문조사 등의 절차는 시도하지 않았으므로 팀장, 파 트장(유닛장) 외에 다른 개념이 존재할 수 있다. 끝으로 임상병리 사관리자 명칭은 병원의 환경에 따라차이는 있겠지만 팀제로 개 편할 경우 팀장, 파트장(유닛장)으로 추진해야한다. 또한 개인이 나 직종의 발전을 위해서 전문임상병리사자격, 국가기술자격, 국가공인민간자격, 학술지논문, 대학원학위, 임상검사경영관리 학에도 각별한 관심을 가져야 한다.

\section{요 약}

2000년대 병원경영전략의 변화로 조직구조가 계층제에서 팀제로 전환되었다. 계층제는 직무 중심, 직책연계, 수직적 관리 가 특징이며 팀제는 직능 중심, 직책분리, 수평적 관리가 특징이 다. 임상병리사 관리자 명칭은 1997년, 2007년, 2017년 세 차 례에 걸쳐서 조사되었다. 수도권에 소재한 500병상 이상의 24 개 병원에서 근무하는 직원들을 통해 확인되었다. 그 결과는 14 개 병원에서 “팀장; 파트장” (59\%), 7 개 병원에서 “기사장; 수석 기사” (29\%), 3개 병원에서 “실장” (12\%) 명칭을 사용 중에 있 다. 본 저자는 임상병리사가 현재 사용하고 있는 세 가지 직위나 직책명칭을 개선하기 위해 팀제를 기반으로 대안을 제안한다. 첫째, 기사장은 기사부장 또는 기사과장인지 지위가 불분명한 명칭이다. 기사장은 “팀장” 으로 변경할 것을 제안한다. 둘째, 수 석기사 또는 계장이 수간호사와 같은 직위 수준이라고 가정한 다면, 수석기사 또는 계장을 파트장(유닛장)으로 변경할 것을 제안한다. 셋째, 직제규정은 계층제의 경우 검사의학과로만 표 기되지만 팀제에서는 검사의학팀으로 표기된다. 임상병리사들 은 팀제를 통해 소속감, 연대감, 친밀감을 더욱 갖게 된다.

\section{Acknowledgements: None \\ Funding: None \\ Conflict of interest: None}

\section{REFERENCES}

1. LEE JS. Hospital management [Internet]. Seoul: Seoul National University College of Medicine; 2017 [cited 2017 November 30]. Available from: http://www.snu-dhpm.ac.kr/pds/files/ \%ЕВ\%B3\%91\%ЕC\%9B\%90\%ЕА\%B4\%80\%EB\%A6\%AC.pdf.

2. Korean Standards Association. Education and training [Internet]. Seoul: Korean Standards Association; 2016 [cited 2017 November 30]. Available from: https://www.ks- 
a.or.kr/ksa_kr/1021/subview.do.

3. Korea Law Information Center. Decree on the appointment of public officials [Internet]. Sejong: Korea Ministry of Government Legislation; 2017 [cited 2018 October 18]. Available from: http://www.law.go.kr/lsInfoP.do?lsiSeq=10106\&ancYd= $19921202 \&$ ancNo=13767\&efYd=19921202\&nwJoYnInfo=N\&ef Gubun=Y\&chrClsCd=010202\#0000.

4. Korea Law Information Center. Guidelines for external title of public officials below 6 grade [Internet]. Sejong: Korea Ministry of Government Legislation; 2017 [cited 2018 October 18]. Available from: http://www.law.go.kr/admRulLsInfoP. do? $\mathrm{chrClsCd}=\&$ admRulSeq=2000000059439.

5. Park WW. Team system in Korea: Characteristics, effectiveness, and future directions. Journal of Korean Business Administration. 2007;41:59-97.

6. Park KO. Team managers' experience with a team system in the hospital. J Korean Acad Soc Nurs Educ. 2012;18(3):486-498.

7. Economic Information and Education Center. New manpower policy following the 5-year plan of the new economy (1993) [Internet]. Sejong: Korea Development Institute; 2015 [cited 2017 November 15]. Available from: http://eiec.kdi.re.kr/policy/material/view.jsp?num=33919\&dcount=30\&searchtopic.

8. Economic Information and Education Center. New manpower policy following the 5-year plan of the new economy (1993) [Internet]. Sejong: Korea Development Institute; 2015 [cited 2017 November 15]. Available from: http://eiec.kdi.re.kr/policy/material/view.jsp?num=33919\&dcount=30\&searchtopic.

9. Bureau of Labor Statistics. Occupational outlook handbook [Internet]. Washington DC: U.S. Department of Labor Statistics; 2017 [cited 2017 November 13]. Available from: https://www.bls.gov/ooh/healthcare/home.htm.

10. IBMS. Biomedical scientist [Internet]. London: Institute of Biomedical Science; 2017 [cited 2017 November 13]. Available from: https://www.ibms.org/about/ibms-history.

11. ASCLS. Clinical laboratory scientist [Internet]. McLean: American Society for Clinical Laboratory Science; 2017 [cited 2017 November 13]. Available from: http://www.ascls.org/ about-us/history.

12. ASCP. Medical laboratory scientist [Internet]. Chicago: American Society for Clinical Pathology; 2017 [cited 2017 November 13]. Available from: https://www.ascp.org/content/docs/pdf/boc-pdfs/procedures/examination-procedures.pdf?sfvrsn=12.

13. Kyoto Prefectural University Hospital. Clinical laboratory [Internet]. Kyoto: Kyoto Prefectural University Hospital.; 2017 [cited 2017 November 17]. Available from: http://www. h.kpu-m.ac.jp/doc/departments/central-sector/department-of-clinical-investigation.html.

14. Cancer Institute Hospital of JFCR. Clinical pathology center [Internet]. Tokyo: Cancer Institute Hospital of JFCR; 2017 [cited 2017 November 17]. Available from: http://www.jfcr.or.jp/ hospital-en/department/clinicopathology/staff.html.

15. Estridge BH, Reynolds AP, et al. Basic medical laboratory techniques. 6th ed.Clifton Park, NY: Delmar cengage learning; 2011.

16. Garcia E, Fisher PB. The American Society for Clinical Pathology's 2013 wage survey of clinical laboratories in the
United States. Am J Clin Path. 2013;44(4):97-115.

17. CLMA. About CLMA [Internet]. Chicago: Clinical Laboratory Management Association; 2017 [cited 2017 November 17]. Available from: http:// www.clma.org/p/cm/ld/fid=4.

18. ASCP. Board of certification [Internet]. Chicago: American Society for Clinical Pathology; 2017 [cited 2017 November 25]. Available from: https://www.ascp.org/content/board-of-certification.

19. AAB. Board of registry [Internet]. Saint Louis: American Association of Bioanalysts; 2017 [cited 2017 November 25]. Available from: https://www.aab.org/aab/AAB_Board_of_Registry.asp.

20. AMT. Get certified [Internet]. Rosemont: American Medical Technologists; 2017 [cited 2017 November 13]. Available from: https://www.americanmedtech.org/Get-Certified.

21. NAACLS. Find a program. Rosemont: National Accrediting Agency for Clinical Laboratory Sciences; 2017 [cited 2017 November 13]. Available from: https://www.naacls.org/Finda-Program.aspx?program.

22. Nadder TS. The development of the doctorate in clinical laboratory science in the US. J Int Fed Clin Chem. 2013;24(1):37-42.

23. CDC. Clinical laboratory improvement amendments [Internet]. Atlanta: Centers for Disease Control and Prevention; 2017 [cited 2017 November 17]. Available from: https://www. ecfr.gov/cgi-bin/text-idx?SID=1248e3189da5e5f936e 5531540 2bc38b\&node $=$ pt $42.5 .493 \&$ rgn $=$ div 5 .

24. Lee WG. Development of administrative system for cooperation body of medical laboratory accreditation. Research report. Cheongju: Korea Centers for Disease Control and Prevention; 2011.

25. CAP. CAP personnel requirements by testing complexity [Internet]. Northfield: College of American Pathologists; 2017 [cited 2017 November 23]. Available from: http://www. cap.org/ShowProperty?nodePath=/UCMCon/Contribution\% 20Folders/WebContent/pdf/personnel-requirements-by-testing-complexity.pdf.

26. ABP. About the ABP [Internet]. Chicago: American Board of Pathology; 2015 [cited 2017 November 17]. Available from: http://www.abpath.org/index.php/taking-an-examination/ examination-dates-deadlines-fees.

27. Department of Health. Medical laboratory board [Internet]. Nashville: State of Tennessee; 2017 [cited 2017 November 17]. Available from: https:/www.tn.gov/content/dam/tn/health/ documents/g4015123.pdf.

28. ABMS. Specialty and subspecialty certificates [Internet] Chicago: American Board of Medical Speciality; 2017 [cited 2017 November 17]. Available from: http://www.abms.org/ member-boards/specialty-subspecialty-certificates.

29. U.S. Centers for Medicare \& Medicaid Services. Certification boards for laboratory directors of high complexity testing [Internet]. Baltimore: U.S. Centers for Medicare \& Medicaid Services; 2017 [cited 2017 November 17]. Available from: https://www.cms.gov/Regulations-and-Guidance/Legislation/ CLIA/Certification_Boards_Laboratory_Directors.html.

30. Koo BK, Sung HJ, Rlee KJ, Yang BS, Joo SI, Choi SG, et al. Fifty years of the Korean Journal of Clinical Laboratory Science: about name and KCI registration. Korean J Clin Lab Sci. 2017;49(3):187-202.

31. Park WW. Team system in Korea: Characteristics, effectiveness, 
and future directions. Journal of Korean Business Administration. 2007;41:59-97.

32. LMF. Resources [Internet]. Seoul: Laboratory Medicine Foundation; 2017 [cited 2017 November 13]. Available from: http://lmf.or.kr/english/sub/catalog.php?Navi=6\&CatNo=61.

33. Lee SM, Suh IB, Yoon SY, Lim CS, Lee KN. Management of clinical laboratory staffs in Korea. J Clin Pathol Qual Control. 2000;22(2):307-312.

34. Suh IB, MA KR, Lee SM, Kwon JA, Bae SY, Lim CS, et al. Management of clinical laboratory staffs in Korea (II). J Lab Med \& Quality Assurance. 2002;24(2):237-242.

35. Korea Health Industry Development Institute. Manpower management and demand of overseas expansion of medical in- stitutions [Internet]. Cheongwon: Korea Health Industry Development Institute; 2016 [cited 2018 January 05]. Available from: https://www.khidi.or.kr/board/view?pageNum=2\&rowCnt= 10\&no1=42\&linkId=161580\&menuId=MENU01196\&maxIndex $=00002174009998 \& \min I n d e x=00001508129998 \&$ schType $=$ $0 \&$ schText=\&boardStyle=\&categoryId $=\&$ continent $=\&$ country .

36. Korea Law Information Center. Occupational Safety and Health Act [Internet]. Sejong: Korea Ministry of Government Legislation; 2017 [cited 2018 October 18]. Available from: http:// www.law.go.kr/\%EB\%B2\%95\%EB\%A0\%B9/\%EC\%82\%B0\%EC\%9 7\%85\%ЕC\%95\%88\%ЕC\%A0\%84\%EB\%B3\%B4\%ЕА\%B1\%B4\%ЕB\% $\mathrm{B} 2 \% 95$. 